\title{
Design and Testing of a Modified Hydroponic Shipping Container System for Urban Food Production
}

\author{
Rachel Elizabeth Sparks, Robert Merton Stwalley III* \\ Email address: \\ sparksr@purdue.edu (R. E. Sparks),rms3@purdue.edu (R. M. Stwalley III) \\ ${ }^{*}$ Corresponding author
}

Department of Agricultural \& Biological Engineering, Purdue University, West Lafayette, USA

\section{To cite this article:}

Rachel Elizabeth Sparks, Robert Merton Stwalley III. Design and Testing of a Modified Hydroponic Shipping Container System for Urban Food Production. International Journal of Applied Agricultural Sciences. Vol. 4, No. 4, 2018, pp. 93-102. doi: 10.11648/j.ijaas.20180404.11

Received: August 7, 2018; Accepted: August 20, 2018; Published: October 10, 2018

\begin{abstract}
In urban centers today, Controlled Environment Agriculture is being proposed as a potential alternative to conventional agriculture using hydroponic methods in controlled spaces as a means to increase local food production and improve urban food security by growing crops. One newly proposed technique, growing crops inside refurbished shipping containers, offers a flexible, mobile, and scalable means of year-round food production in a variety of climates. Despite the benefits of producing food locally, some concerns associated with shipping container systems include high-energy consumption from climate control and electric lightning systems, as well as expensive capital investments. This study investigated the viability and effectiveness of shipping container farms as alternative food production systems through an analysis of system energy requirements and resulting crop yields. A Modified Hydroponic Shipping Container system was designed and a Nutrient Film Technique hydroponics system was tested by growing lettuce plants and monitoring energy use throughout the growth period. Theoretical energy use at full scale was quantified for one year of production by modeling energy consumption of major system components through modeling or extension from results on the bench scale. Baseline crop production and overall energy consumption were assessed using a crop production efficiency metric created to evaluate the ratio of system outputs to inputs. Examination of alternative energy scenarios showed potential energy consumption reductions of up to 53 percent and an improvement of the total system crop production efficiency of up to 55 percent from the baseline. Implementation of suggested energy use reduction strategies could allow for the creation of viable and sustainable alternative food systems using shipping containers capable of providing local, accessible foods year-round for a variety of urban communities.
\end{abstract}

Keywords: Controlled Environment Agriculture, Crop Production, Energy Consumption, Hydroponics, Shipping Container, Vertical Farming, Urban Agriculture

\section{Introduction}

Globally, an increasing number of people live in cities. In 2014 , it was estimated that $54 \%$ of the world's population lived in urban areas. This figure is projected to grow to $66 \%$ by 2050 , which is a significant increase from 1950, when only $30 \%$ of the world's population was considered [1]. As the populations grows, so does the amount of food that must be allocated to people living in urban areas. The 2015 Sustainable Development Goals defined by the United Nations General Assembly highlighted methods for addressing the multi-faceted challenges facing urban centers today. Specifically, Goal 9: build resilient infrastructure, promote sustainable industrialization, and foster innovation and Goal 11: make cities inclusive, safe, resilient, and sustainable emphasize the importance of maintaining and improving urban resources, while reducing overall consumption as the world population continues to grow and urbanize [2].

Currently, many urban areas around the world do not exemplify the characteristics of sustainable, resilient cities, but rather act as large nutrient and resource sinks. In many metropolitan food systems, food items are constantly imported from distant rural areas with large agricultural output for consumption by the urban population [3]. However, the process of growing, producing, and transporting food is very energy intensive. For example, it is estimated that food systems in the United States use between 12 and $20 \%$ of all US 
energy consumption, and fresh produce in the US is transported 1500 miles on average from farm-to-table [4]. Unfortunately, much agricultural production for human consumption is specialized by location. Conventional food systems offer uniformly high productivity and efficiency, but they also require extensive water, fertilizer, and pesticide use to grow crops [5], as well as a high-quality infrastructure and efficient distribution routes to deliver foods to consumers [6]. Additionally, conventional food production and distribution systems systematically exclude those living in food deserts, defined in the 2008 Farm Bill as areas "in the United States with limited access to affordable and nutritious food, particularly such an area composed of predominantly lower income neighborhoods and communities" [7]. Access to healthy food in food deserts is limited by both economic and geographic barriers, which often reduces food choices for low-income communities to processed, fast, and commodity foods [8].

One response to the problems inherent in conventional food systems has been the increased utilization of urban agriculture, simply defined as the growing of plants and the raising of animals within and around cities [9]. Growing crops in close proximity to the source of consumption offers several environmental, economics, and social benefit. Crops produced locally reduce the need for packaging, storage, and transportation of food, which can save energy and reduce food waste. Additionally, organic wastes produced in cities are often recycled by urban farmers to produce compost $[3,6]$. Urban agriculture also has an enormous impact on improving health and economic conditions of the urban poor. Improved access to fresh produce and other agricultural products decreases malnutrition and nutrient deficiencies [6]. When families are able to supplement their diets with homegrown foods they might not otherwise be able to afford, this not only improves their nutrition, but it also increases the amount of income that they can set-aside for other nonfood expenses, such as education [3]. From the producer's perspective, fruits and vegetables are high value crops that can serve as an important source of income for small-scale urban farmers [6].

In developed regions, Controlled Environment Agriculture (CEA) is becoming an increasingly popular method for cultivation crops in urban centers. CEA exists at the intersection of urban agriculture and technology, as crops are grown indoors in controlled spaces, often utilizing hydroponic growth methods. CEA methods manipulate the five cardinal factors of plant growth: light, temperature, water, nutrients, and atmosphere, and they provide an optimal growing space for plants [10]. CEA has been promoted as a sustainable alternative to conventional agriculture systems. Since the overall environment is controlled, these systems can produce food year-round, with significantly lower water requirements than conventional agriculture, and they reduce outside contamination of production zones and eliminate the need for significant amounts of pesticides or herbicides to be applied to plants [11, 12].

Methods for farming indoors range widely, and one particularly intriguing form of CEA is a hydroponic production system installed within a shipping container. These units are known as Modified Hydroponic Shipping Containers (MHSC) Companies, such as Freight Farms ${ }^{\mathbb{B}}$ (Boston, MA) and Podponics ${ }^{\circledR}$ (Atlanta, GA), provide commercially available MHSC modules that offer "high volume crop production units that can be quickly set up and easily operated to grow food in any environment. Each unit can create local food economy to empower communities to reduce the global footprint of food in a sustainable and profitable manner." [13]. The Leafy Green Machine $^{\circledR}$, produced by Freight Farms ${ }^{\circledR}$ and shown in figures 1 and 2 , is one example of a shipping container that has been retrofitted to produce leafy greens and lettuces (Lachea Sahv L.) year round.

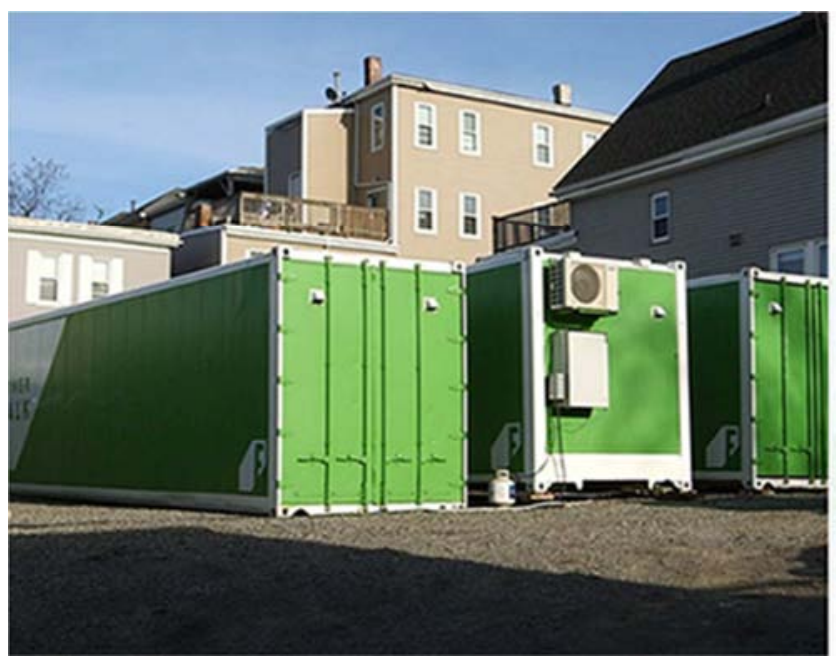

Figure 1. Exterior view of Freight Farms ${ }^{\circledR}$ Leafy Green Machines ${ }^{\circledR}$ [16].

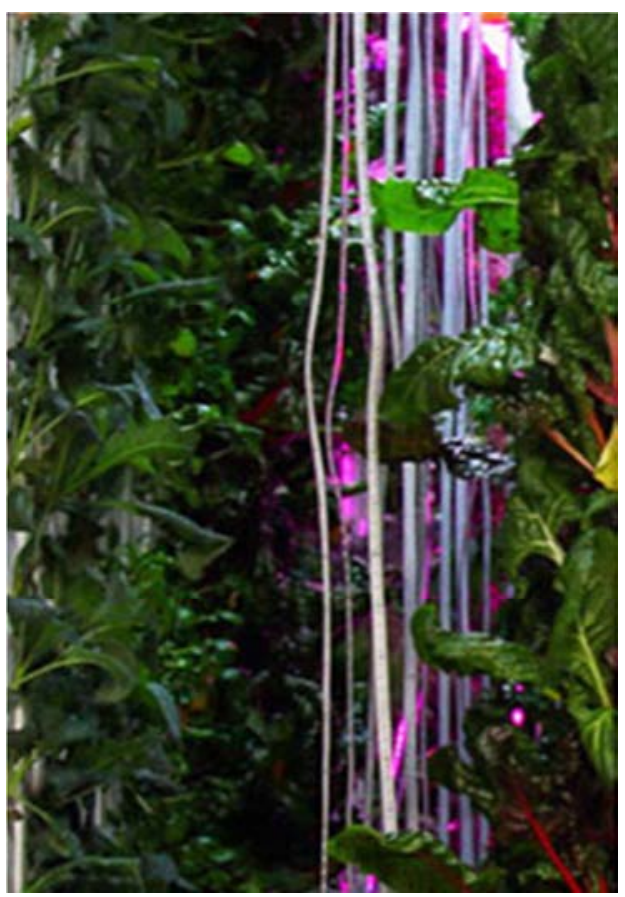

Figure 2. Interior view of Freight Farms ${ }^{\circledR}$ Leafy Green Machines ${ }^{\circledR}$ [16].

Despite the potential benefits of mobile, year-round food production, the economic viability of shipping container farms and other CEA systems remain a concern, due to the 
high-energy costs and capital investments are required to operate such systems. High-energy use in CEA systems is an issue that brings into question the effectiveness and sustainability of this type of food production [14]. Lighting, along with heating and cooling loads, has been identified as the largest consumer of energy in CEA systems [15]. Problematically, shipping container farms require 100 percent electric lighting, since the stackable units do not allow for individual unit crop exposure to direct sunlight. Needing high profit margins, shipping container farms currently focus only on the production of fast leafy green crops, such as lettuce (Lactuca sativa) and spinach (Springeia oleracea), or high value herbs, such as basil (Ocimum basilicum) and parsley (Petroselinum crispum). It should also be noted that CEA-grown vegetables often sell for a premium price at high-end supermarkets [17], which unfortunately does not help address the problem of unbalanced diets and malnutrition in food deserts. Further study on the energy and production efficiency of these containers farms is needed to understand whether a wider diversity of crops grown with these systems can be economically supported.

The quantification of the energy requirements and crop production potential of shipping container farms remains to be adequately documented in the literature, and steps to rectify this shortcoming were undertaken [18]. The Purdue Agricultural \& Biological Engineering department's Urban Agriculture Initiative (UAI) team had previously begun an investigation into the viability and effectiveness of shipping container farms as an alternative food production system and had a research MHSC under construction. Initial efforts were focused on developing an appropriate production metric to analyze the MHSC system and creating a thermal model for the overall system to aid in making informed design choices regarding the physical structure and operating protocols for the unit. A Nutrient Film Technique (NFT) hydroponics system was designed for the Purdue MHSC [19], and it was tested on a bench scale with head lettuce as the production crop. Plant location illumination, mechanical power requirement, and harvest weight of the lettuce crop from the bench system were specifically examined in this study. A model for estimating total system energy use was also developed based on the Purdue MHSC physical design. Results from crop production and energy consumption model were analyzed to determine a baseline Crop Production Efficiency (CPE) for the system. Scenarios for improvement in order to increase the baseline CPE value and provide a pathway forward for creation of a viable, sustainable method of alternative food production were provided. It was reasonably shown from an analysis of the energy requirements and resulting crop yield that significant work in the area remains to be completed in order to make MHSC units into competitive crop production venues.

\section{Materials \& Methods}

The results of the experimental testing reported here are the baseline and scoping investigations for the Purdue UAI-designed MHSC. This process was undertaken to un- derstand the relative range of values that could be expected within a modern MHSC. This section will describe the physical Purdue MHSC design and the engineering thermal modeling of the unit. This work was designed to measure the unknown energy consumption levels of specific power-consuming elements of the NFT system in operation and to establish a potential baseline of crop productivity for the specific Purdue NFT design.

\subsection{Purdue MHSC System Design}

In order to create an optimal useful hydroponic food production system housed in a shipping container, several design constraints were identified. First, the MHSC needed to be able to produce a diversity of crops within a variety of locations and climates, and basic growing parameters needed to be flexible to aid overall system evaluation. Operational variability was required for the final system design in hydroponic tube slope, nutrient height in growth tube, nutrient flow rate through growth tube, lighting position, ventilation rate, and environmental conditions. The unit needed to be able to be transported and replicated easily, in order to meet changing food production demands. Additionally, the system needed to be simple to operate, without requiring extensive expertise in hydroponics. Finally, the MHSC needed to be able to produce a high crop yield in an energy efficient manner. Therefore, to meet these constraints, the Purdue MHSC needed to exhibit the following characteristics in its general design: mobility, flexibility, modularity, simplicity, productivity, and efficiency. One of the main objectives of this study, to determine a baseline unit productivity, would be directly affected by the design choices that increased or decreased crop yield and energy use. The most important factors for maximizing crop yields were therefore considered to be the type of hydroponic delivery, the quality of lighting system, and the suitability of the interior environment. To minimize energy use, factors such as amount of heating, cooling and ventilation (HVAC) necessary to control the MHSC environment, the efficiency of lighting systems, and degree of system automation were considered to be the most important. Both productivity and efficiency factors were examined to maximize the space available within the MHSC.

A standard 'high cube" 40' x 8' x 9' foot shipping container unit was used as the beginning element of the Purdue MHSC design. The NFT was determined to be the most applicable hydroponic delivery method for use in the MHSC following an initial Purdue ABE senior capstone design team analysis [19]. These systems offer high water efficiency and ample oxygenation to root systems. The baseline design and layout are depicted from profile and overhead viewpoints in figures 3 and 4, respectively. The Purdue MHSC unit contains four of these grow plots capable of holding 84 plants, each. Each plot is made of four PVC pipes, 15 feet in length that drain to a single reservoir with space for 21 plants in each PVC pipe. 


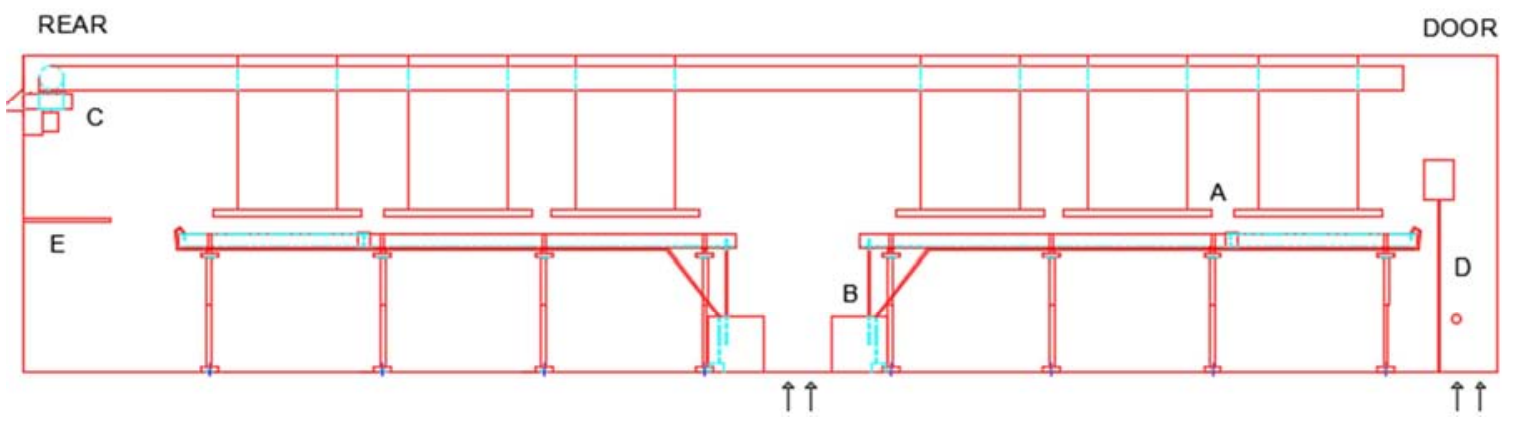

$A=$ Lighting Fixtures, $D=$ Service Entrances, $B=$ Nutrient Recirculation System, $C=$ Ventilation System, $E=S$ Storage

Figure 3. Purdue MHSC baseline design profile view [20].

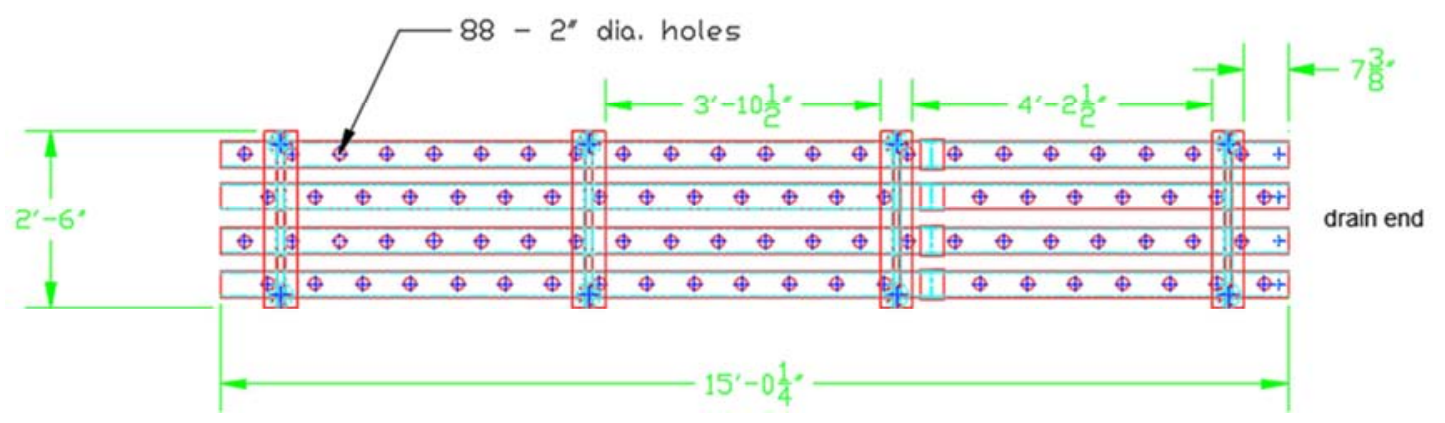

Figure 4. Purdue MHSC baseline design profile view [20].

\subsection{Full-Scale Energy Modeling}

The energy model utilized a steady-state energy balance concept and was applied at the boundary of the MHSC in order to determine the amount of active heating or cooling energy required to maintain an optimal interior temperature $\left(68^{\circ} / 59^{\circ} \mathrm{F} ; 12 h\right.$ day/12 $h$ night) [10]. All sources of heat gain and loss in the shipping container were considered throughout a theoretical design year, and then the energy balance was applied to the system to determine values for hourly heating and cooling loads. The shipping container boundary served as the control volume, and Lafayette, Indiana, was used as the shipping container location for the energy balance analysis. Sources of heat gain and heat loss are listed in tables 1 and 2, respectively.

Table 1. Sources of heat gain in the MHSC baseline energy model.

\begin{tabular}{ll}
\hline Heat Gain & Variable Name \\
\hline Conduction gain through walls, floor, and roof & $\mathrm{Q}_{\text {stht }}$ \\
Ventilation gain through air inlet and outlet & $\mathrm{Q}_{\mathrm{vtht}}$ \\
Mechanical heat gains from lighting & $\mathrm{Q}_{\mathrm{me}}$ \\
Heat load delivered by HVAC equipment & $\mathrm{Q}_{\mathrm{prht}}$ \\
\hline
\end{tabular}

Table 2. Sources of heat loss in the MHSC baseline energy model.

\begin{tabular}{ll}
\hline Heat Gain & Variable Name \\
\hline Conduction loss through walls, floor, and roof & $\mathrm{Q}_{\text {stht }}$ \\
Ventilation loss through air inlet and outlet & $\mathrm{Q}_{\mathrm{vtht}}$ \\
Conversion of sensible heat to latent heat during & $\mathrm{Q}_{\mathrm{me}}$ \\
evapotranspiration & $\mathrm{Q}_{\text {prht }}$ \\
Cooling load removed by HVAC equipment & \\
\hline
\end{tabular}

For the condition of thermal equilibrium, it may be assumed that the components of tables 1 and 2 are in balance, as expressed mathematically in equation 1 . Based on the types of heat gain and loss for the system, the four main thermal energy pathways were determined to be structural conduction, conduction through ventilation, mechanical generation, and evapotranspiration. Structural conduction was based upon the driving potential of the ambient external condition of the shipping container, accounting for solar insolation and static temperature. Equation 2 represents the detailed expansion of the heat balance for the MHSC. Conduction and ventilation values used in equation 2 only represent a net contribution to the energy balance, and heating loads were considered to be negligible during cooling periods, and vice versa. There were no significant exposed-to-air open nutrient solution surfaces to contribute to the evapotranspiration term. The final determination of net heat gain or loss through these four components allowed the subsequent overall cooling load for the MHSC unit during hot weather to be calculated through the use of equations 2 and 3 [21]. Overall heating load for the MHSC unit in cold weather was quantified through the use of equations 2 and 4.

$$
\begin{gathered}
\mathrm{Q}_{\text {gain }}=\mathrm{Q}_{\text {loss }} \\
\mathrm{Q}_{\text {stht }}+\mathrm{Q}_{\mathrm{vtht}}+\mathrm{Q}_{\mathrm{me}}+\mathrm{Q}_{\text {prht }}=\mathrm{Q}_{\text {strcl }}+\mathrm{Q}_{\mathrm{vtcl}}+\mathrm{Q}_{\mathrm{et}}+\mathrm{Q}_{\mathrm{prcl}} \\
\mathrm{Q}_{\text {prcl }}=\mathrm{Q}_{\text {stht }}+\mathrm{Q}_{\mathrm{vtht}}+\mathrm{Q}_{\mathrm{me}}-\mathrm{Q}_{\mathrm{et}} \\
\mathrm{Q}_{\text {prht }}=\mathrm{Q}_{\text {stcl }}+\mathrm{Q}_{\mathrm{vtcl}}+\mathrm{Q}_{\mathrm{et}}-\mathrm{Q}_{\mathrm{me}}
\end{gathered}
$$

After heat gains and losses from $\mathrm{Q}_{\text {stht }}, \mathrm{Q}_{\mathrm{vth}}, \mathrm{Q}_{\mathrm{me}}$, and $\mathrm{Q}_{\mathrm{et}}$ were determined for each hour of the design year, a summation of the hourly values for $\mathrm{Q}_{\text {prcl }}$ were calculated. Similarly, 
values for $\mathrm{Q}_{\text {stcl }}, \mathrm{Q}_{\mathrm{vtcl}}$ were calculated for the quantification of $Q_{\text {prht. }}$ These heat quantity values represented the energy requirement necessary to maintain the optimal interior temperature conditions in the MHSC at each hour of the design year. Knowledge of the maximum and minimum power requirements for heating and cooling the unit allowed mechanical HVAC equipment to be properly sized for the space. Quantification of the total power required to run all electrical systems at full scale represented the system "input," for the determination of CPE. An evaluation of individual energy components in this manner can also be used as a comparison between various design alternatives.

\section{Experimental Design}

To establish the baseline production metrics for the Purdue hydroponic design in the shipping container, a prototype unit was built to represent one grow plot, or $25 \%$ of the full system crop production capacity. A standard hydroponic nutrient solution was created using reverse osmosis water and $2.0 \mathrm{ml} / 1$ of FloraMicro ${ }^{\circledR}, 2.6 \mathrm{ml} / 1$ of FloraGro ${ }^{\circledR}$, and $0.7 \mathrm{ml} / 1$ of FloraBloom ${ }^{\circledR}$ fertilizers from General Hydroponics ${ }^{\circledR}$ (Sebastopol, CA). Burpee Butter Bowl lettuce was grown from seeds in a nursery environment with Rapid Rooter ${ }^{\mathbb{B}}$ plant starter plugs from General Hydroponics (Sebastopol, CA) as shown in figure 5 . The nursery received half strength nutrient solution and a 24 photoperiod from American Fluorescent ${ }^{\circledR}$, (New York, NY) high performance fixtures with two T18 Daylight $\left(6500^{\circ} \mathrm{K}\right)$ fluorescent bulbs $14 \mathrm{~cm}$ above the grow surface. After three weeks, the plants were transplanted into the bench scale prototype NFT system shown in figure 6 . The photoperiod was reduced to 18 hours using the similar lighting units, and nutrient solution was circulated at a rate of $650 \mathrm{~L} / \mathrm{h}$ throughout the entire four growth tube system. The plants were allowed to grow over a period of 36 days, as shown in figure 7 . Three consecutive lettuce growth cycles, now referred to as Cycle 1, Cycle 2, and Cycle 3, were carried-out over a period roughly three months, from March 10, 2016 to May 27, 2016, in an environmentally controlled Purdue ABE laboratory facility. The air temperature in this facility was allowed to vary between $64^{\circ}$ and $74^{\circ} \mathrm{F}$ according to the operational protocols of the lab. Periodic ambient air temperature checks throughout the testing period confirmed these conditions. Each sample lettuce plant was harvested at the conclusion of the cycle and weighed on a total fresh weight basis. The total fresh weight yield during each cycle represented the system "output" term and served as an indicator for production performance of the system.

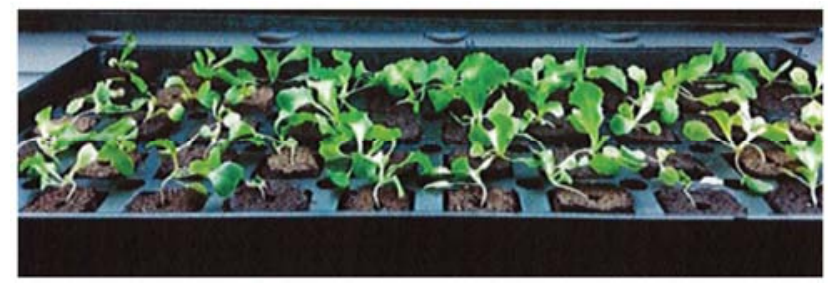

Figure 5. Nursery stage production system for lettuce crop [18].

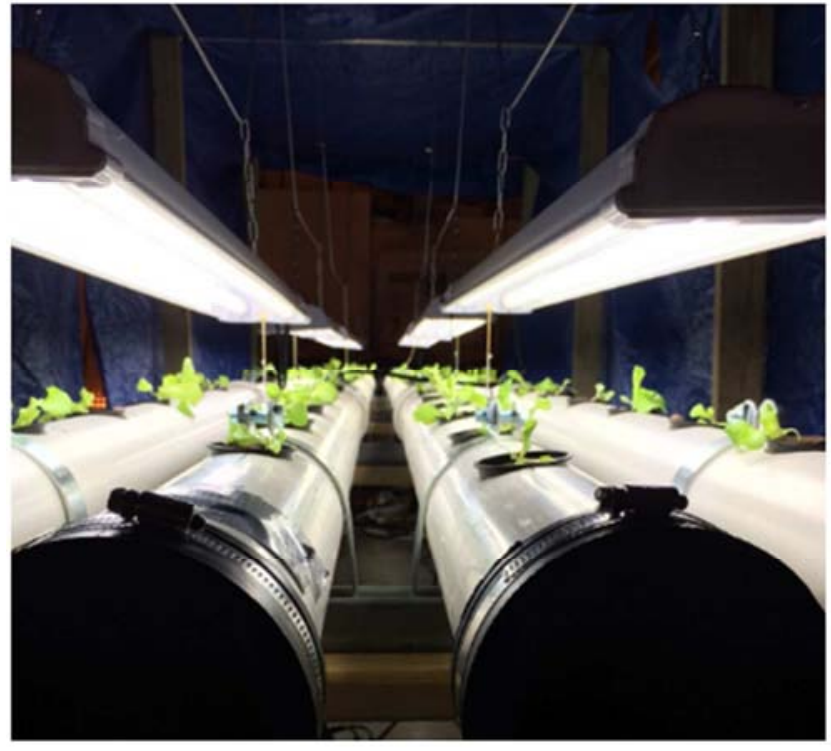

Figure 6. Purdue NFT prototype production system following crop transplant [18].

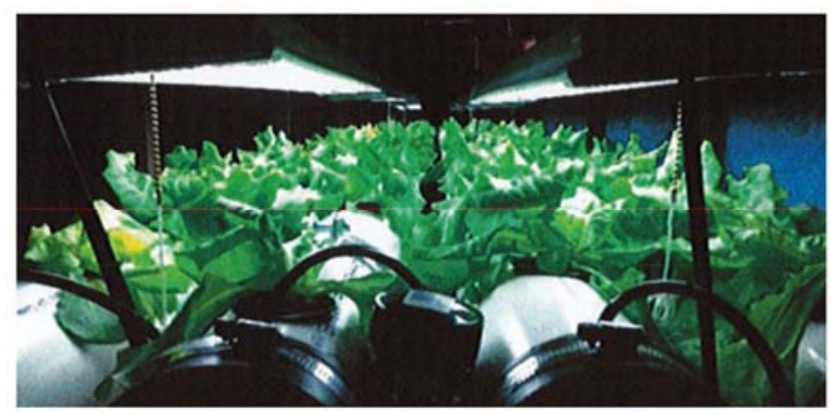

Figure 7. Purdue NFT prototype production system at harvest, day 36 [18].

Plant production yield, or "output," was one of two factors in CPE. The "input" term was the second required value to compute a baseline CPE value for the MHSC, and this factor included all electrical power consumption by the system. To determine total system power consumption, electrical components were monitored in the prototype NFT system, and an energy model was created for estimating consumption at full-scale. In the NFT prototype system, electric lighting, water pumping, and air circulation components were monitored continuously. The energy model for full-scale MHSC system would include the same lighting, pumping, and air circulation components values for the calculation of Qme, but the overall value would increase proportionally to the volume of the MHSC.

\section{Results \& Discussion}

The data collected during this investigation consisted of biomass weights, electrical energy usages, and lighting illuminance values. Weights were measured using an Ohaus ${ }^{\circledR}$ (Florham Park, NJ) triple beam balance, with an advertised accuracy of $\pm 0.1 \mathrm{~g}$. Once properly balanced, the scale showed no measurable variance using known test weight samples of 250, 500, and $750 \mathrm{~g}$. Electrical energy usage values were 
recorded using a Kill-a-Watt ${ }^{\circledR}$, commercially available energy consumption measurement device from P3 International, Corp. dba Intertek $^{\circledR}$ (New York, NY), with an advertised accuracy of $\pm 0.2 \%$. Illuminance data values were collected using a FLIR Commercial Systems, Inc. dba Extech $^{\circledR}$ (Nashua, NH) HD 450 datalogging light meter, with an advertised accuracy of $\pm 5.0 \%$. Conversion of the kLux readings to photosynthetically active radiation (PAR) value was done through estimation procedures [22, 23]. All data readings were collected in accordance with the instrument manufacturer's instructions and the accepted practices of good scientific inquiry.

\subsection{Lettuce Production}

The total fresh biomass weight yield represented the "output" term for the CPE metric, and the results from each lettuce production cycle are displayed in table 3. Columns A, B, C, and $D$ represent one of four tubes in the prototype NFT system, from left to right respectively in figure 3 . Each cycle was 36 days from seed germination to harvest, with the exception of Cycle 2, in which plants were harvested after only 28 days. During Cycle 2, an unidentified contaminant began adhering to some roots and started causing suffocation on day 25 . The early harvest occurred in order to prevent the onset of Pythium, commonly known as root rot [24].

Table 3. Lettuce production cycle fresh weight yields.

\begin{tabular}{llllll}
\hline Cycle & A $(g)$ & B $(g)$ & C $(g)$ & TOTAL $(g)$ & 919.3 \\
\hline Cycle 1 & 414.3 & 134.1 & 141.0 & 229.9 & 67.5 \\
Cycle 2 & 67.5 & 59.9 & 74.1 & 623.1 & 686.2 \\
Cycle 3 & 615.2 & 686.8 & 623.9 & 2612.2 \\
\hline
\end{tabular}

The total fresh weight and uniformity of samples in each cycle were considered the best measures of lettuce production success, since vegetables purchased in grocery stores by consumers are priced either by weight or by number. A hypothetical market or store would therefore want to sell produce that is both uniform and large enough to provide consumers a quality selection of food items to choose from. Based on the total fresh weight in Cycle 3 from Table 3, as well as the distribution of sample fresh weights shown in figure 6 , the initial results showed that there was a sizable variation in sample size and uniformity. Cycle 1 had several data points flagged as outliers by the Minitab ${ }^{\circledR}$, Inc. (State College, PA) statistical package. In Figure 8, the boxes represent the middle $50 \%$ of the data. The criteria for the whiskers in the plot is an additional 1.5 box heights above or below the box. Outliers beyond the bounds are individually marked. In addition to the large variation in individual plant yields, the production rate in all three cycles was much lower than current commercial standards. Hydroponic lettuce producers in Hawaii have managed to achieve yields of up to $300 \mathrm{~g} / \mathrm{ft}^{2}$ [25]. According to the University of Illinois Extension [26], butter lettuce should typically weigh $110-230 \mathrm{~g}$ at harvest, but the largest overall yield in this study only reached $20 \%$ of the target commercial fresh weight. The average weights per head in all cycles of this study were much lower than this targeted amount.

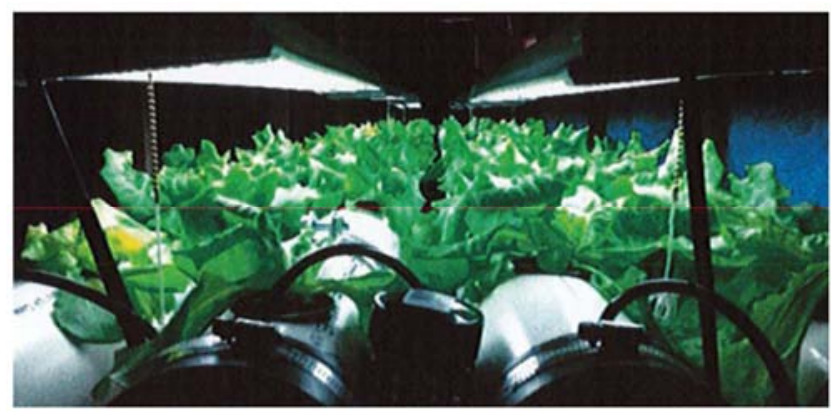

Figure 8. Distribution of fresh weight samples for Cycles 1, 2, and 3.
The low, irregular production rate issues were clearly based on the lack of operational experience with the NFT system and its complexities. Failure to insure plant health and adequately provide the cardinal factors of CEA [10] stunted production. Figure 6 certainly showed that as experience was gained with the system over time, the results improved. During Cycle 1, there were nutrient flow rate problems which were eventually resolved. Cycle 2 aptly drove-home the necessity of thorough NFT system sanitizing between growth cycles, while Cycle 3, which built upon these experiences, demonstrated higher overall growth. It is likely that continued utilization and growth in experience base will continue to improve the "output" results achievable from this system.

The poor performance on the production side of the investigation did not affect the collection of mechanical energy data for the input side. Energy consumption values for lighting, pumping, and ventilation are presented later in the section on MHSC energy modeling. One particular cardinal factor was demonstrated to have positive effect on plant growth in all cases. Figures 9 through 11 show the relationship between the PAR at a specific growth locations and the biomass produced in that location for Cycles 1, 2, \& 3, respectively. Although the data indicate a fairly high variance in biomass weight, the PAR values were determined to have a significant positive effect on the dependent variable in all cases.

In all three cycles, PAR at each tray position significantly affected the final fresh weight of the corresponding sample. The relationship between these two variables was most significant in Cycle 3. The wide range of PAR values recorded and presented in figures 9 through 11 clearly show variability in PAR measured at each individual tray position. This analysis also showed that larger lettuce heads could be attributed at least partially to greater PAR at the corresponding tray position. Adequate lighting amounts and the uniformity of its coverage in the growth area are clearly key factors that will strongly influence the success of plant production in MHSC units. 


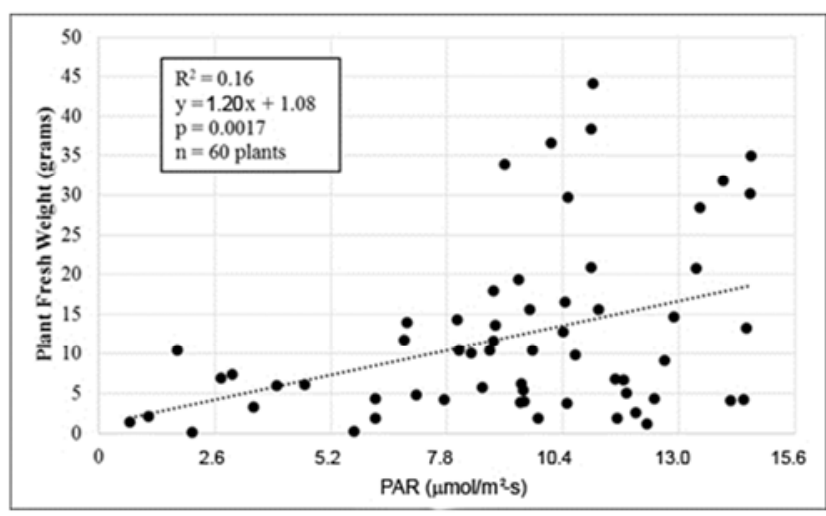

Figure 9. Cycle 1 illuminance regression analysis.

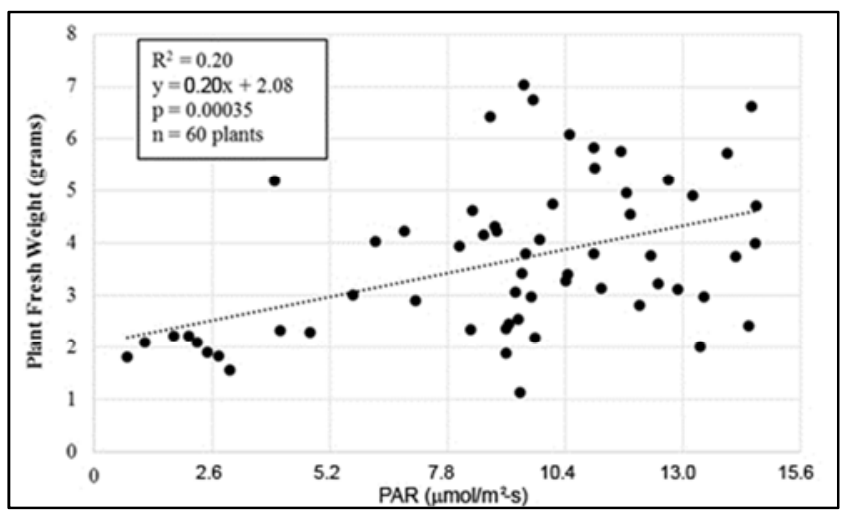

Figure 10. Cycle 2 illuminance regression analysis.

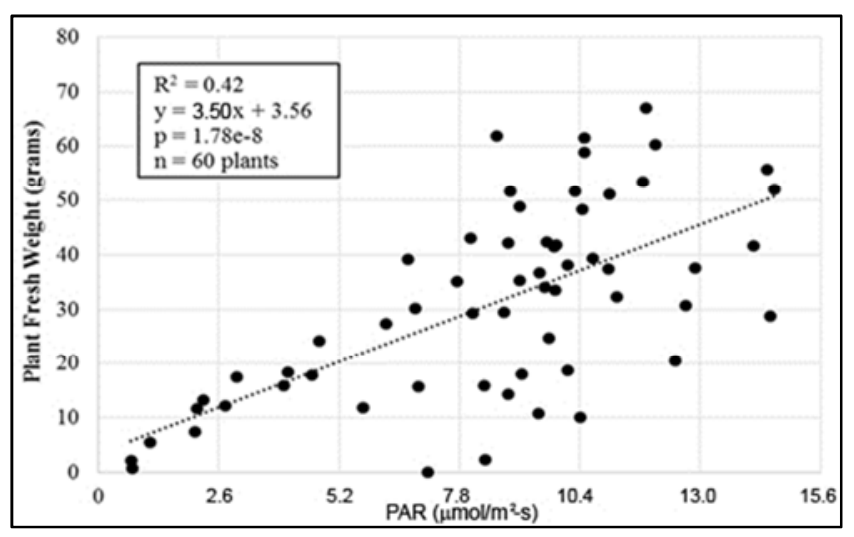

Figure 11. Cycle 3 illuminance regression analysis.

\subsection{Energy Modeling}

Monthly results for the individual components of the baseline energy model are listed in table 4 . These results are differentiated into overall energy consumption values for each of the four main components in the energy model: $\mathrm{Q}_{\mathrm{st}}, \mathrm{Q}_{\mathrm{vt}}, \mathrm{Q}_{\mathrm{me}}$, $\& \mathrm{Q}_{\mathrm{et}}$. The active heating and cooling energy requirement was calculated as the thermal balance for each month. Positive values are a gain to the structure. Conductive heat transfer into the structure was modeled using the current physical structure of the MHSC and the difference between the required internal environment and the expected annual weather conditions in Lafayette, Indiana. A full-scale shipping container farm is exposed to fluctuations in external temperature, solar radiation, and humidity, all of which affect the power load required to maintain optimal plant growth temperatures in CEA systems [27, 28, \& 29]. As expected, the gradient for conductive heat transfer cycles throughout the year. Exposure to the projected ambient environment consisted of both radiative and convective interactions. The RTS model of Spitler, Fisher, \& Pedersen [30] was used to calculate heat transfer through the container for the thermal model. Convective ventilation heat transfer was based upon the energy required to condition the optimal amount of make-up air needed for plant growth in the MHSC. Convective heat transfer also varied in an expected manner during the course of the year. Similarly, the model of Albright [21] was used to calculate convective heat transfer for the interior of the MHSC. Air exchange rates within the MHSC were determined by selecting the optimum values recommended by Buffington, et al. [31]. Mechanical energy generation values were estimated based upon the experimental data taken over the course of this investigation. The measured sub-components were energy for lighting, pumping nutrient solution, and mechanically operating the ventilation system. These sub-components represented approximately $85 \%, 10 \%$, $\& 5 \%$ of the total mechanical energy, respectively. The evapotranspiration values were determined from the Priestley-Taylor plant growth model of Sumner \& Jacobs [32]. The active energy transport required to maintain a thermal condition in the optimal zone was determined using equation 3 or 4 . The months of May through September are net cooling periods, while October through April are net heating periods.

Table 4. Baseline energy consumption by model component.

\begin{tabular}{|c|c|c|c|c|c|}
\hline Month & $\begin{array}{l}\text { Structural }-Q_{\text {st }} \\
(k W-h)\end{array}$ & $\begin{array}{l}\text { Ventilation }-Q_{v t} \\
(k W-h)\end{array}$ & $\begin{array}{l}\text { Mechanical - } Q_{\mathrm{me}} \\
(k W-h)\end{array}$ & $\begin{array}{l}\text { Transpiration }-Q_{\mathrm{et}} \\
(k W-h)\end{array}$ & $\begin{array}{l}\text { Heating \& Cooling }-Q_{p r} \\
(k W-h)\end{array}$ \\
\hline January & $3248(-)$ & $2143(-)$ & $1166(+)$ & $61(-)$ & $4727(+)$ \\
\hline February & $2797(-)$ & $1798(-)$ & $1053(+)$ & $55(-)$ & $4199(+)$ \\
\hline March & $1946(-)$ & $830(-)$ & $1175(+)$ & $59(-)$ & $4185(+)$ \\
\hline April & $803(-)$ & $297(+)$ & $1154(+)$ & $54(-)$ & $2974(+)$ \\
\hline May & $183(+)$ & $1771(+)$ & $1217(+)$ & $119(-)$ & $3052(-)$ \\
\hline June & $805(+)$ & $5123(+)$ & $1194(+)$ & $977(-)$ & $6145(-)$ \\
\hline July & $967(+)$ & $6718(+)$ & $1235(+)$ & $1650(-)$ & $7270(-)$ \\
\hline August & $825(+)$ & $5341(+)$ & $1233(+)$ & $954(-)$ & $6445(-)$ \\
\hline September & $328(+)$ & $2133(+)$ & $1183(+)$ & $190(-)$ & $3454(-)$ \\
\hline October & $876(-)$ & $262(+)$ & $1196(+)$ & $58(-)$ & $3042(+)$ \\
\hline November & $1856(-)$ & $776(-)$ & $1138(+)$ & $57(-)$ & $4106(+)$ \\
\hline December & $2938(-)$ & $1831(-)$ & $1167(+)$ & $60(-)$ & $4591(+)$ \\
\hline
\end{tabular}


Since active thermal control accounted for nearly $80 \%$ of the total energy requirement throughout the design year, it was most important factor for improvement in the MHSC operational design. Structural conduction and ventilation convection contributed the largest heating and cooling loads in the model. Reducing the heat transfer associated with these components increased the thermal efficiency of the modeled MHSC, thereby allowing the system to maintain optimal plant growth temperatures with less energy dedicated to thermal control. Demonstrating the effects of these principles, three alternative design and operational scenarios were considered:

1) Follow common practice for inhabited structures and improve the insulation value of the MHSC by replacing the 2 " extruded polystyrene (XPS) rigid foam board with 2" of closed cell spray polyurethane foam (SPF) on all surfaces and increasing the $\mathrm{R}_{\mathrm{eff}}$ for the unit from 5.00 to 6.25 [33];

2) Accept a less than optimal air quality condition during extreme thermal difference periods and reduce the ventilation air exchange rates to a level midway between the optimum and minimum rates [31]; and

3) Utilize Scenario 1 and 2 together.
Using the output data from the current investigation, the CPE values were projected for each operational scenario are displayed in table 5. Figure 12 shows how the model calculates the net required energy profiles for the various scenarios across the year. Clearly using this model, different strategies may lead to better results at varying times of the year.

Unfortunately, the CPE values for both the baseline and alternative scenarios are still too low to be viable, due to overall low lettuce production rates and high-energy consumption. Improvements in mechanical efficiency, as well as biological yield, would have the potential to increase the CPE to a point where crop production in the MHSC might be feasible on a commercial scale. Improved LED lighting and other precision control technologies may improve crop yields significantly, and high value crops are clearly advantageous for production operations in these types of units. These CPE values and other analyses provide a preliminary assessment of what may be possible in the full-scale Purdue MHSC system at its current state of development, and the factors input into the defined production metric, $\mathrm{CPE}$, indicate where potential improvements can be made.

Table 5. Crop production efficiency at full-scale.

\begin{tabular}{|c|c|c|c|c|}
\hline Cycle & Baseline CPE $(g / k W-h)$ & Scenario 1 CPE $(g / k W-h)$ & Scenario 2 CPE $(g / k W-h)$ & Scenario 3 CPE $(g / k W-h)$ \\
\hline Cycle 1 Production Rate & 0.54 & 0.66 & 0.83 & 1.15 \\
\hline Cycle 1 Production Rate & 0.16 & 0.19 & 0.24 & 0.34 \\
\hline Cycle 1 Production Rate & 1.50 & 1.90 & 2.30 & 3.30 \\
\hline
\end{tabular}

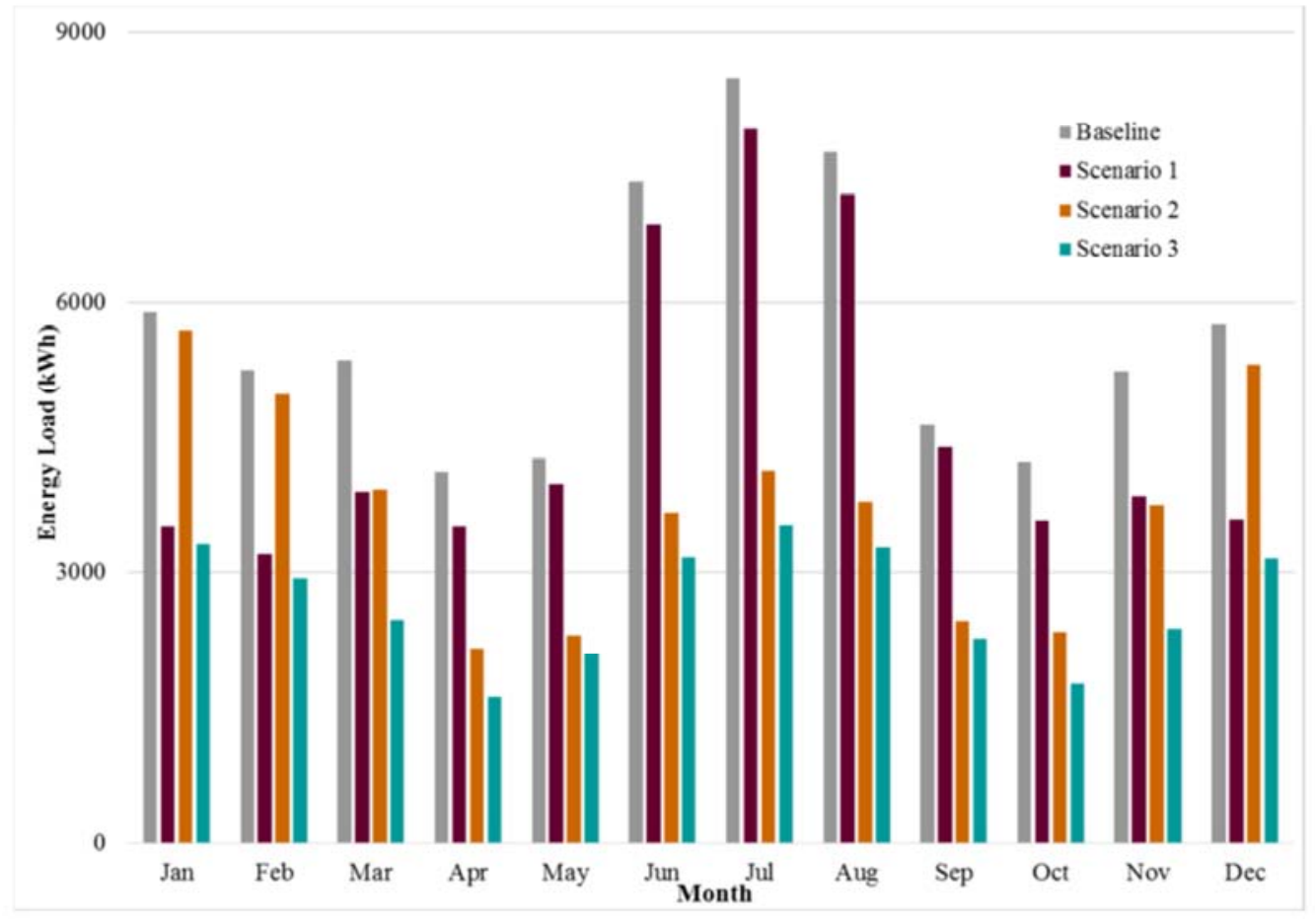

Figure 12. Comparison of the annual Purdue MHSC thermal model using various operational conditions.

\section{Conclusions}

Based on the results of lettuce production and energy modeling which corresponded to the $\mathrm{CPE}$ values presented, it was determined that in its current state, the Purdue MHSC was not a viable substitute for commercial food production for urban communities. The study objectives were completed successfully and several conclusions can be drawn from the 
work presented:

1) The average fresh weight per head of lettuce produced in the NFT Test Unit during each cycle was much lower than current commercial yields, and the largest harvest in Cycle 3 only reached $20 \%$ of the $300 \mathrm{~g} / \mathrm{ft}^{2}$ target for the hydroponic lettuce production.

2) Operational experience was a huge factor in the successful cultivation of a crop.

3) PAR at each tray position significantly affected the final fresh weight of the corresponding sample in all three cycles.

4) Mechanical power was tracked in a component-based manner for the prototype NFT growth system.

5) The baseline energy model of the MHSC successfully provided a comprehensive picture of the power consumption over one design year.

6) Alternative design scenarios for the MHSC and reduced ventilation protocols demonstrated methods of reducing yearly energy consumption up to $53 \%$ of the baseline model total.

7) From results of lettuce production and energy modeling, both experimental and theoretical crop production efficiency values were too low for current MHSC design to be economically viable for commercial lettuce production.

As a food production system for urban spaces, there is significant room for improvement in the overall MHSC design. To be a truly sustainable and effective method of producing food, the overall energy consumption in the full scale MHSC must be reduced, and the NFT design must be further refined in order to increase the lettuce yields and improve uniformity. If these types of systems are to become competitive with current commercial and industrial vegetable producers, both factors in CPE must improve dramatically. The mobile flexible elements of the Purdue MHSC design do offer a unique local urban alternative to industrial farming, and this design could potentially decrease the distance and energy required to transport food to consumers. The key to the successful introduction of this technology will be the long-term economic operational costs of the technology. The proper modeling and management of energy costs will be central to this optimization.

Both vertical farming and hydroponic systems are promising technologies with significant potential. These innovative concepts deserve further attention and study, as local sustainable food production methods are vital to creating global food production and distribution systems for a continuously urbanizing world. Although this investigation was initially unsuccessful in production, the Purdue MHSC design demonstrated several interesting design possibilities for vertical hydroponic growing with mobile unit applications. With further improvements to the design components, the reduction of specific system energy loads, and an improvement in yield, the MHSC could become one of many solutions improving the way food is grown and consumed. However, more research, innovation, and entrepreneurship in this field will certainly be needed to make it possible for this type of food production system to become economically viable.

\section{Acknowledgements}

The assistance of EEI, Inc. and the Purdue University Department of Agricultural \& Biological Engineering in the conduction of this work is hereby gratefully acknowledged.

\section{References}

[1] United Nations - Department of Economic and Social Affairs Population Division. (2015). World urbanization prospects: The 2014 revision. New York: United Nations.

[2] United Nations General Assembly Resolution 70/1. (2015, September 25). Transforming our world: The 2030 agenda for sustainable development. Retrieved from un.org.

[3] Mougeot, L. J. (2006). Growing better cities: Urban agriculture for sustainable development. Ottawa, ON: International Development Research Centre.

[4] Durham, L., \& Oberhotlzer, L. (2010). A geographic approach to place and natural resource use in local food systems. Renewable Agriculture and Food Systems, 25(2), 99-108.

[5] Gold, M. V. (2007, August 6). Sustainable agriculture: definitions and terms. Retrieved from afsic.nal.usda.gov.

[6] Orsini, F., Kahane, R., Nono-Womdim, R., \& Gianquinto, G. (2013). Urban agriculture in the developing world: A review. Agronomy for Sustainable Development, 33, 695-720.

[7] USDA (United States Department of Agriculture). (2009). Access to affordable and nutritious food: Measuring and understanding food deserts and their consequences - A Report to Congress. Washington, DC: USDA.

[8] Alkon, A. H., \& Norgaard, K. M. (2009). Breaking the food chains: An investigation of food justice activism. Sociological Inquiry, 79(3), 289-305.

[9] FAO (Food and Agriculture Office of the United Nations). (2016, June 6). Urban agriculture. Retrieved from fao.org.

[10] Mitchell, C. A. (2012). Plant lighting in controlled environments for space and earth applications. Acta Horticulturae, 956, 23-36.

[11] Despommier, D. (2010). The vertical farm: Controlled environmental agriculture carried-out in tall buildings would create greater food safety for large urban populations. Jouranl fur Verbraucherschutz und Lebensmittelsicherheit (Journal of Consumer Protection and Food Safety), 6, 233-236.

[12] Jensen, M. J. (2010). Controlled Environmental Agriculture in Deserts, Tropics, and Temperate Regions - A World Review. University of Arizona Controlled Environmental Agricultural Center Paper \#I-125933-03-00.

[13] Schnitzler, W. H. (2013). Urban hydroponics for green and clean cities and for food security. Acta Horticultrae, 1004, 13-26.

[14] The Economist. (2010, December 9). Does it really stack up? Retrieved from exonomist.com. 
[15] Barbosa, G. L., Gadelha, F. D., Kublik, N., Proctor, A., Reichelm, L., Weissinger, E., Wohleb G. M., \& Halden, R. U. (2015). Comparison of land, water, and energy requirements of lettuce grown using hydroponic vs. conventional agricultural methods. International Journal of Environmental Research and Public Health, 12, 6879-6891.

[16] Anashkina, A. (2015). Cornerstalk, outside and in. Retrieved from money.cnn.com.

[17] Brennan, M., \& Gralnick, J. (2015, June 24). Vertical farming the next big thing for food and tech. Retrieved from cnbc.com.

[18] Sparks, R. E. (2016). Mapping and Analyzing Energy Use and Efficiency in a Modified Hydroponic Shipping Container. MS Thesis, Purdue University, Agricultural \& Biological Engineering, W. Lafayette.

[19] Rathbun, K., Sparks, R., \& Wright, K. (2014). Development of a Hydroponic System for Use in Developing Countries. ABE 484-486 Capstone Experience Final Report, Purdue University, Agricultural \& Biological Engineering Department, W. Lafayette.

[20] Houtman, J. A. (2016). Design and Plan of a Modified Hydroponic Shipping Container for Research. MS Thesis, Purdue University, Agricultural \& Biological Engineering Department, W. Lafayette.

[21] Albright, L. D. (1990). Environmental Control for Animals and Plants (Vol. Series 4). St. Joseph, MI: American Society of Agricultural Engineers.

[22] PARsource. (2018). Light Unit Conversion Table. Retrieved from parasource.com/content/light-unit-conversion-table.

[23] Riddle, D. (2013). Aquarium equipment: PAR meters and LEDs - how accurate are these measurements? Retrieved from https://www.advancedaquarist.com/2013/2/equipment.
[24] Pennsylvania State University Extension. (2016). Pythium. Retrieved from http://extension.psu.edu/pests/plant-disease/all-facts/sheets/pyt hium.

[25] Valenzuela, H. R., Kratky, B. L., \& Cho, J. (1996). Lettuce Production Guidelines for Hawaii (Vol. Series 164). Honolulu, HI: Hawaii Institute of Tropical Agriculture and Human Resources.

[26] University of Illinois Extension. (2016, June 6). Lettuce. Retrieved from extension.illinois.edu.

[27] Kreith, F., \& Kreider, J. F. (1978). Principles of Solar Engineering. Washington, DC: Hemisphere Publishing Corporation.

[28] Vanek, F., Albright, L. D., \& Anagenent, L. (2016). Energy Systems Engineering: Evaluation and Implementation. New York: McGraw-Hill Education.

[29] Goswami, D. (2015). Principles of Solar Engineering. Boca Raton: CRC Press.

[30] Spitler, J. D., Fisher, D. E., \& Pedersen, C. O. (1997). The Radiant Time Series Cooling Load Calculation Procedure. ASHRAE Transactions, 3(2).

[31] Buffington, D. E., Bucklin, R. A., Henley, R. W., \& McConnell, D. B. (2016). Greenhouse Ventilation. University of Florida, IFAS Extension, Gainesville.

[32] Sumner, D. M., \& Jacobs, J. M. (2005). Utility of Penman-Monteith, Prestley-Talyor reference evapotranspiration, and pan evaporation methods to estimate pasture evapotranspiration. Journal of Hydrology, 308, 81-104.

[33] Martin, R. L. (2014, December). R Value Table. Retrieved from coloradoenergy.org. 